\title{
Editorial
}

\section{Smart Service Systems: An Interdisciplinary Perspective}

\author{
Daniel Beverungen, Christoph F. Breidbach, Jens Poeppelbuss and Virpi Kristiina Tuunainen
}

\section{Introduction}

Smart service systems are upon us. Fuelled by unprecedented advances in connectivity, sensors, data storage and computation (Beverungen et al. 2019), smart service systems are valuecocreating configurations of people, technologies, organisations and information, which are capable of independent learning, adaptation and decision making (National Science Foundation 2014, p. 5). The smart service that such systems are capable of rendering is pre-emptive in its behaviour, adaptive to customer needs and contexts, thereby exceeding traditional offerings with respect to both perceived customer value and provider efficiency (Allmendinger and Lombreglia 2005). Smart service systems have emerged in contexts as diverse as manufacturing, logistics, mobility, healthcare and private living. For example, digitally connected aircraft engines report status data in real time, enabling predictive maintenance and pay-per-use business models. Cars analyse driving behaviour based on sensor data, schedule workshop appointments and provide optimised eco-feedback to drivers. Public trash bins equipped with sensors track the volume and kinds of garbage to help calculate the type and number of collection vehicles to be dispatched and the time of the collections, thus increasing efficiencies of operation and cost savings. Wearable systems monitor people's health status and support their personalised treatment.

Smart service systems are a prime example to illustrate the growing convergence and reinforcement of two key developments of our time: digital transformation (Matt et al. 2016) and servitisation (Vandermerwe and Rada 1988; Baines et al. 2009). Service industries have for a long time served as a key application area for the use of, and innovation with, digital technology (Breidbach and Maglio 2015). Consequently, calls for more research linking information systems (IS) research with services have emerged (Rai and Sambamurthy 2006). Following the same trajectory, the intersection of big data analytics and service innovation has also emerged as a key research priority for service research (Ostrom et al. 2015), with contributions investigating topics ranging from the applications of machine learning to the integration of service innovations and design (Antons and Breidbach 2018) and the ethical implications of data analytics (Someh et al. 2019). Similarly, digital technology is a key enabler of new value propositions that underpin the transition of manufacturing firms as they become service and solution providers (Lerch and Gotsch 2015). Bringing both trends together, Sklyar et al. (2019) have even introduced the notion of digital servitisation.

Both IS and service (marketing) research have begun to explore the critical intersection of digital technology and service more generally, which has led to some important special issues in both marketing (Huang and Rust 2013) and IS (Barrett et al. 2015) journals. However, the academic research community appears to be struggling in its attempts to overcome the current

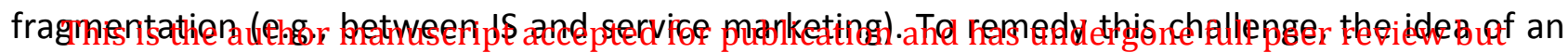

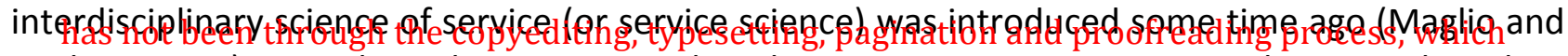
Spohrer 2008).dAs a boundary-spanning discipline serviçe science aims to dessign and analyse configuratigns of value-cocreating actors, focusing on the service system as the basic unit of analysis (Maglio and Breidbach 2014). 
With this special issue, we wish to extend the recent academic discussion related to smart service systems beyond IS research, offering an interdisciplinary perspective that is centred on the idea of a boundary-spanning service science. In what follows, we discuss in more detail how an interdisciplinary perspective on smart service science can be of great value to academia in general and IS research in particular. This is followed by a brief summary of the papers featured in this special issue. Finally, we provide conclusions and perspectives on future interdisciplinary research on smart service systems.

\section{An Interdisciplinary Perspective on Smart Service Systems}

Service science aims to offer an interdisciplinary perspective on the study of service systems by combining "organization and human understanding with business and technological understanding to categorize and explain the many types of service systems that exist as well as how service systems interact and evolve to co-create value" (Maglio and Spohrer 2008, p. 18). Here, service is commonly understood as "the application of specialized competencies [...] through deeds, processes, and performances for the benefit of another entity" (Lusch and Vargo 2006, p. 283 , italics contained in the text), with value created with, and determined by, a beneficiary. As such, the emergence and perception of value are disconnected from the exchange of goods or services and, consequently, from their costs (Vargo and Lusch 2008). Service science views the service system as its basic unit of analysis. A service system is "a configuration of people, technologies, and other resources that interact with other service systems to create mutual value" (Maglio et al. 2009, p. 395). Maglio et al. (2009) explain that many systems can be viewed as service systems, including individuals, corporations, foundations, non-governmental organisations, non-profits, government agencies, departments in an organisation, cities, nations and families. Multiple service systems can together form composite service systems (e.g., a service customer that contracts a service provider organisation in a market-based arrangement). Such compositions and, hence, service systems are dynamic, as they are composing, recomposing and decomposing over time (Maglio et al. 2009).

The attribute smart, which takes centre stage in this present special issue, highlights that digital technology allows for the transformation of service systems into smart service systems. In smart service systems, technology resources (i.e., smart products) serve as boundary objects that provide a shared identity and local usefulness to the different service systems that together engage in the cocreation of value-in-use (Beverungen et al. 2019; Becker et al. 2013). The omnipresence of digital technology has dramatically boosted the number and accessibility of resources that lend themselves to being coupled with service systems. In other words, information systems liquefy resources (Barrett et al. 2015; Lusch and Nambisan 2015) and make them accessible for recombinant innovation in ever-changing service systems (Beverungen et al. 2018). Consequently, smart service systems need to be understood as complex, open and dynamic sociotechnical systems.

Adopting this interdisciplinary perspective offers significant contributions to the IS discipline in its attempt to analyse and design smart service systems. First, the aforementioned service science concepts provide IS scholars with an alternative and flexible unit of analysis. While IS research has analysed and designed information systems with a focus on either individuals, groups, organisations or markets (Sidorova et al. 2008), service science sees the service system as an 
inclusive construct and thereby facilitates the analysis of the nested and dynamic sets of actors and roles that we observe in smart service systems.

Second, service science postulates the integration of resources to cocreate value-in-use for people, organisations and society. Information systems can be interpreted as resources that service systems can use to perform activities and interact with others to cocreate value-in-use in a particular context. Hence, service science's inherent focus on value cocreation provides an additional lens for many constructs and metrics used in the IS discipline, including individual user acceptance, IT adoption and corporate economic success. It further emphasises the relevance of the context in which value cocreation happens, which tends to be complex and dynamic.

Third, taking a boundary-spanning perspective, service science provides a common ground for weaving together theories and IT artefacts that originate from multiple disciplines to develop an academic foundation for a systematic study of technology-enabled and -supported services (Maglio and Breidbach 2014). Service science can act as a vehicle that enables IS scholars to take up concepts and theories originating in neighbouring research disciplines, as well as making IS concepts and theories accessible outside the IS discipline. This is particularly important as we are seeing a convergence of developments in practice and research that have conceptually different roots (e.g., IS, service marketing, computer science, mechanical engineering and innovation research).

Taken together, an interdisciplinary perspective on smart service systems offers opportunities to extend and refine some of the IS discipline's core constructs, intensify collaborations with other disciplines to increase the recognition and impact of contributions beyond the borders of our field, and focus our research efforts on providing results that have societal relevance.

\section{Overview of the Papers in this Special Issue}

The papers published in this special issue investigate different facets of smart service systems. In "Capturing Smart Service Systems: Development of a Domain-Specific Modelling Language", Rocco Huber, Louis Püschel and Maximilian Röglinger design a conceptual modelling language for smart service systems. Based on an understanding of systems as nodes and interactions, their modelling language revisits and integrates traditional service concepts, adding "smart things" and "digital hubs" as decisive components of smart service systems. The modelling language, therefore, serves to clarify the inner structure of smart service systems, making them accessible as a detailed unit of analysis and design. The modelling language considers the autonomous nature of smart things observing themselves and their environment through sensing capabilities to be an important construct of a smart service system. More precisely, the authors discuss observation, interaction and parametrisation as phenomena of "relationships" among "resources". Following up on their design, the authors demonstrate and evaluate their modelling language with scenarios of Internetof-Things-based service systems, a conceptual evaluation and an empirical evaluation conducted with industry experts.

In the second paper, "Configuration in Smart Service Systems: A Practice-Based Inquiry", Lauri Wessel, Elizabeth Davidson, Ana Paula Barquet, Hannes Rothe, Oliver Peters and Herlind Megges analyse configuration processes in human-centred smart service systems. The authors report on an interdisciplinary study at the intersection of medicine, service science and IS research that deals with smart locating systems used in the home care of persons with dementia. In this study, 
they focus on humans as one of the key elements of service system configurations, analysing the role of human actors in particular (rather than smart technologies). The authors collected data through interviews with and observations of 20 dyads of persons with dementia and their family caregivers, who attempted to integrate smart technologies into their practices relating to location control. The authors identify three varied configurations of how location control was enacted (enhanced, degraded and fragile smartness) and derive a process model for configuring service in practice. Informed by practice theory, the study discloses the internal operations of service systems in terms of mutual configuring and reinforcing interactions, whose goal is that the system should be able to structure itself as a result of the smart technologies integrated into the system from the outside.

\section{Conclusions and Perspectives}

Investigating smart service systems provides a unique opportunity for stimulating the advancement of interdisciplinary research. It offers a chance to investigate IS from novel perspectives, connect with neighbouring disciplines, and design and use IS to create value-in-use for people, organisations and society. Achieving this will require the adoption of a service-science perspective in IS research. Likewise, the IS discipline has much to contribute to the emerging service science. Future research should help fuel this mutual exchange of ideas, concepts and theories.

An obvious common denominator of IS and service science that needs further theoretical elaboration is the notion of a system. While references to general systems theory (GST) can be found in both disciplines (see e.g., Maglio et al. 2009; Garrity 2001), it appears that there has been little consideration of the implications of applying a systems perspective to the concepts and phenomena under study. Spohrer et al. (2008) and Maglio et al. (2009) rather swiftly introduced the notion of the service system as the "basic abstraction in service science", without thoroughly embedding it into established concepts of GST. To further strengthen the service system's unifying properties as a theoretical lens, we suggest revisiting and extending the concept in line with GST. Since the principles of GST have been widely taken up by many academic disciplines, they may provide a suitable foundation for establishing consistent concepts and theories across service science, IS and other disciplines.

We further see the need to explore the dual nature of information systems as resources that help to both manage and increase the complexity of service systems. Smart service systems tend to be particularly complex, as they usually involve more actors than just a service provider and a service customer that are connected through digital technology. The actors have to agree on structuresranging from organisational roles to communication protocols-to reduce complexity to a manageable degree. Since information systems have proven their value for managing complexity (Helbing et al. 2015), it seems fair to assume that they will play a role in establishing and managing (hyper-)complex (smart) service systems. However, the idea of reducing complexity by building additional system structures may again increase complexity (Abbasi et al. 2016).

While this editorial provides a starting point for further exploring the complex interplay of service systems and information systems, we call on the IS community as well as the service science community to increase their efforts to conduct joint research. By establishing interdisciplinary teams of researchers from neighbouring disciplines, we can better learn about the complex 
interplay of digital technology and service systems in so far as it is observable from smart service systems.

\section{Acknowledgements}

As guest editors, we would like to thank the authors and reviewers who dedicated their efforts to this special issue. We would also like to thank Editor-in-Chief Robert Davison and former Editor-inChief Eileen Trauth, who both supported us in initiating this special issue. This work is part of a project that has received funding from the European Union's Horizon 2020 research and innovation programme (Marie Skłodowska-Curie grant agreement No. 645751).

\section{References}

Abbasi, Ahmed; Sarker, Suprateek; Chiang, Roger (2016): Big Data Research in Information Systems: Toward an Inclusive Research Agenda. In Journal of the Association for Information Systems 17 (2), pp. I-XXXII. DOI: 10.17705/1jais.00423.

Allmendinger, Glen; Lombreglia, Ralph (2005): Four Strategies for the Age of Smart Services. In Harvard Business Review 83 (10), 131-4, 136, 138 passim.

Antons, D. and C. Breidbach, F, (2018). "Big Data, Big Insights? Advancing Service Innovation and Design With Machine Learning." Journal of Service Research 21(1): 17-39.

Baines, T.; Lightfoot, H.; Benedettini, O.; Kay, J. (2009): The Servitization of Manufacturing. In Journal of Manufacturing Technology Management 20 (5), pp. 547-567. DOI: 10.1108/17410380910960984.

Barrett, Michael; Davidson, Elizabeth; Prabhu, Jaideep; Vargo, Stephen L. (2015): Service Innovation in the Digital Age: Key Contributions and Future Directions. In MIS Quarterly 39 (1), pp. 135-154. DOI: 10.25300/MISQ/2015/39:1.03.

Becker, Joerg; Beverungen, Daniel; Knackstedt, Ralf; Matzner, Martin; Mueller, Oliver; Poeppelbuss, Jens (2013): Bridging the Gap Between Manufacturing and Service Through IT-Based Boundary Objects. In IEEE Transactions on Engineering Management 60 (3), pp. 468-482. DOI:

10.1109/TEM.2012.2214770.

Beverungen, Daniel; Luettenberg, Hedda; Wolf, Verena (2018): Recombinant Service Systems Engineering. In Business \& Information Systems Engineering 60 (5), pp. 377-391. DOI: 10.1007/s12599018-0526-4.

Beverungen, Daniel; Mueller, Oliver; Matzner, Martin; Mendling, Jan; Vom Brocke, Jan (2019): Conceptualizing smart service systems. In Electronic Markets 29 (1), pp. 7-18. DOI: 10.1007/s12525017-0270-5.

Breidbach, C. F. and P. P. Maglio (2015). A Service Science Perspective on the Role of ICT in Service Innovation. ECIS 2015 Münster, Germany.

Garrity, Edward J. (2001): Synthesizing User Centered and Designer Centered IS Development Approaches Using General Systems Theory. In Information Systems Frontiers 3 (1), pp. 107-121. DOI: 10.1023/A:1011457822609. 
Helbing, Dirk; Brockmann, Dirk; Chadefaux, Thomas; Donnay, Karsten; Blanke, Ulf; Woolley-Meza, Olivia et al. (2015): Saving Human Lives: What Complexity Science and Information Systems can Contribute. In Journal of Statistical Physics 158 (3), pp. 735-781. DOI: 10.1007/s10955-014-1024-9.

Huang, Ming-Hui; Rust, Roland T. (2013): IT-Related Service. In Journal of Service Research 16 (3), pp. 251-258. DOI: 10.1177/1094670513481853.

Lerch, Christian; Gotsch, Matthias (2015): Digitalized Product-Service Systems in Manufacturing Firms: A Case Study Analysis. In Research-Technology Management 58 (5), pp. 45-52. DOI: $10.5437 / 08956308 \times 5805357$.

Lusch, Robert F.; Nambisan, Satish (2015): Service Innovation: A Service-Dominant Logic Perspective. In MIS Quarterly 39 (1), pp. 155-175. DOI: 10.25300/MISQ/2015/39.1.07.

Lusch, Robert F.; Vargo, Stephen L. (2006): Service-dominant logic: reactions, reflections and refinements. In Marketing Theory 6 (3), pp. 281-288. DOI: 10.1177/1470593106066781.

Maglio, P. P.; Spohrer, J. (2008): Fundamentals of service science. In Journal of the Academy of Marketing Science 36 (1), pp. 18-20. DOI: 10.1007/s11747-007-0058-9.

Maglio, Paul P.; Breidbach, Christoph F. (2014): Service Science: Toward Systematic Service System Innovation. In Alexandra M. Newman, Janny Leung, J. Cole Smith, Harvey J. Greenberg (Eds.): Bridging Data and Decisions: INFORMS, pp. 161-170.

Maglio, Paul P.; Vargo, Stephen L.; Caswell, Nathan; Spohrer, Jim (2009): The Service System is the Basic Abstraction of Service Science. In Information Systems and e-Business Management 7 (4), pp. 395-406. DOI: 10.1007/s10257-008-0105-1.

Matt, C.; Hess, T.; Benlian, A.; Wiesboeck, F. (2016): Options for Formulating a Digital Transformation Strategy. In MIS Quarterly Executive (15(2)). DOI: 10.7892/boris.105447.

National Science Foundation (2014): Partnerships for Innovation: Building Innovation Capacity (PFI:BIC). Program Solicitation NSF14-610.

Ostrom, Amy L.; Parasuraman, A.; Bowen, David E.; Patrício, Lia; Voss, Christopher A. (2015): Service Research Priorities in a Rapidly Changing Context. In Journal of Service Research 18 (2), pp. 127-159. DOI: 10.1177/1094670515576315.

Rai, Arun; Sambamurthy, Vallabh (2006): Editorial Notes-The Growth of Interest in Services Management: Opportunities for Information Systems Scholars. In Information Systems Research 17 (4), pp. 327-331. DOI: 10.1287/isre.1060.0108.

Sidorova; Evangelopoulos; Valacich; Ramakrishnan (2008): Uncovering the Intellectual Core of the Information Systems Discipline. In MIS Quarterly 32 (3), p. 467. DOI: 10.2307/25148852.

Sklyar, Alexey; Kowalkowski, Christian; Tronvoll, Bård; Soerhammar, David (2019): Organizing for Digital Servitization: A Service Ecosystem Perspective. In Journal of Business Research 104, pp. 450460. DOI: 10.1016/j.jbusres.2019.02.012.

This article is protected by copyright. All rights reserved. 
Someh, I.; Davern, M.; Breidbach, C.F.; Shanks, G. (2019). "Ethical issues in big data analytics: A stakeholder perspective." In Communications of the Association for Information Systems 44(1): pp. 718 $-747$

Spohrer, Jim; Vargo, Stephen L.; Caswell, Nathan; Maglio, Paul P. (2008): The Service System Is the Basic Abstraction of Service Science. In J. Spohrer, S. L. Vargo, N. Caswell, P. P. Maglio (Eds.): The Service System Is the Basic Abstraction of Service. ScienceProceedings of the 41st Annual Hawaii International Conference on System Sciences (HICSS 2008). 2008 41st Annual Hawaii International Conference on System Sciences. Waikoloa, HI, 07.01.2008 - 10.01.2008: IEEE, p. 104.

Star, Susan Leigh (2010): This is Not a Boundary Object: Reflections on the Origin of a Concept. In Science, Technology, \& Human Values 35 (5), pp. 601-617. DOI: 10.1177/0162243910377624.

Star, Susan Leigh; Griesemer, James R. (1989): Institutional Ecology, 'Translations' and Boundary Objects: Amateurs and Professionals in Berkeley's Museum of Vertebrate Zoology, 1907-39. In Social Studies of Science 19 (3), pp. 387-420. DOI: 10.1177/030631289019003001.

Vandermerwe, Sandra; Rada, Juan (1988): Servitization of business: Adding value by adding services. In European Management Journal 6 (4), pp. 314-324. DOI: 10.1016/0263-2373(88)90033-3.

Vargo, Stephen L.; Lusch, Robert F. (2004): The Four Service Marketing Myths. In Journal of Service Research 6 (4), pp. 324-335. DOI: 10.1177/1094670503262946.

Vargo, Stephen L.; Lusch, Robert F. (2008): Service-dominant Logic: Continuing the Evolution. In Journal of the Academy of Marketing Science 36 (1), pp. 1-10. DOI: 10.1007/s11747-007-0069-6.

Wessel, Lauri; Davidson, Elizabeth; Barquet, Ana; Rothe, Hannes; Peters, Oliver; Megges, Herlind. Configuration in Smart Service Systems: A Practice-Based Inquiry. Information Systems Journal (To Press)

Huber, Rocco; Püschel, Louis; Röglinger, Maximilian. Capturing Smart Service Systems - Development of a Domain-specific Modeling Language. Information Systems Journal (To Press) 


\section{University Library}

\section{- M M I E E R VA A gateway to Melbourne's research publications}

Minerva Access is the Institutional Repository of The University of Melbourne

Title:

Smart service systems: An interdisciplinary perspective

Date:

2019-11-01

Citation:

(2019). Smart service systems: An interdisciplinary perspective. Wiley-Blackwell Publishing Ltd.. https://doi.org/10.1111/isj.12275.

Persistent Link:

http://hdl.handle.net/11343/286551 